\title{
Estudo da adsorção do surfatante catiônico brometo de cetiltrimetil amônio em diferentes matrizes inorgânicas preparadas via nióbio metálico
}

\section{(Adsorption study of the cationic surfactant cetyl trimethylammonium bromide onto hydrous niobium oxide matrix)}

\author{
P. H. F. Pereira, A. L. C. Peixoto, M. L. C. P. Silva \\ Departamento de Engenharia Química, Laboratório de Novos Materiais, Escola de Engenharia de Lorena - \\ EEL Universidade de S. Paulo - USP, Estrada Municipal do Campinho, s/n, Bairro Campinho, C.P. 116, Lorena, \\ SP 12602-810 \\ mlcaetano@dequi.eel.usp.br
}

\begin{abstract}
Resumo
É mostrada a preparação de diferentes materiais inorgânicos a partir de nióbio metálico e seu comportamento no processo de adsorção de brometo de cetiltrimetil amônio (CTABr). Os materiais inorgânicos estudados são o óxido de nióbio e o fosfato de nióbio hidratado. Os óxidos de nióbio foram obtidos pelo método da precipitação em solução homogênea com a decomposição térmica de $\left(\mathrm{NH}_{4}\right)_{2} \mathrm{CO}_{3}$ realizada a $45{ }^{\circ} \mathrm{C}$ e a $90^{\circ} \mathrm{C}$. O fosfato de nióbio hidratado foi obtido pela dissolução do nióbio metálico a uma mistura de ácido fluorídrico e nítrico e adição de ácido fosfórico. Pelo método de adsorção gasosa (BET) e por microscopia eletrônica de varredura verificou-se que os materiais não apresentam mudança significativa nas características físicas. As isotermas de Langmuir e de Freundlich revelaram que o melhor resultado de adsorção do surfactante CTABr foi alcançado para o óxido de nióbio hidratado preparado a $90{ }^{\circ} \mathrm{C}$, com capacidade de adsorção máxima, segundo modelo de Langmuir, com 14,13 mg.g ${ }^{-1}$.

Palavras-chave: óxido de nióbio hidratado, isotermas de Langmuir e de Freundlich, surfactante CTABr.
\end{abstract}

\begin{abstract}
The preparation in inorganic material different from metallic niobium and its effect onto adsorption process of the cetyl trimethylammonium bromide CTABr is reported. The inorganic materials are studied niobium oxide hydrous and niobium phosphate hydrous. The niobium oxide hydrous were obtained by homogeneous solution precipitation method with thermal decomposition of $\left(\mathrm{NH}_{4}\right)_{2} \mathrm{CO}_{3}$ at $45{ }^{\circ} \mathrm{C}$ and $90{ }^{\circ} \mathrm{C}$. The niobium phosphate hydrous were prepared using of metallic niobium dilution in a mixture of fluoridric/nitric (10:1) and after phosphoric acid addition. Through the BET method and the SEM technique it was verified that the material suffer no significant change in the physical characteristics. The Langmuir and Freundlich isotherms showed better result to surfactant CTABr adsorption using the material prepared at $90{ }^{\circ} \mathrm{C}$, according to Langmuir model with maximum adsorption capacity of $14.13 \mathrm{mg} \cdot \mathrm{g}^{-1}$.
\end{abstract}

Keywords: niobium hydrous oxide, Langmuir and Freundlich isotherms, CTABr surfactant.

\section{INTRODUÇÃO}

Adsorção é um dos processos mais eficientes no tratamento avançado de efluentes, o qual indústrias empregam para reduzir nos efluentes compostos perigosos tanto orgânicos como inorgânicos. Esse processo é também utilizado para remover compostos tóxicos orgânicos e inorgânicos provenientes de lençóis freáticos contaminados [1]. A aplicação de materiais inorgânicos no processo de adsorção por troca iônica surgiu com o uso de produtos naturais como argilas, zeólitas e ácidos húmicos no tratamento de água. No entanto, o primeiro trocador iônico utilizado comercialmente foi o gel de aluminossilicato amorfo, muito embora o mesmo apresente instabilidade química diante de soluções ácidas [2]. Houve um interesse considerável na preparação e aplicação de materiais inorgânicos para troca iônica nas últimas quatro décadas, em decorrência das condições favoráveis destes materiais se comparados com as resinas orgânicas. Dentre as vantagens destes trocadores iônicos estão estabilidade em meio ácido à moderadamente alcalino, alta seletividade e resistência à altas temperaturas e radiação $[3,4]$. As principais classes destes materiais incluem fosfatos insolúveis, arsenatos, tungstatos, molibdatos, hexacianoferratos e óxidos hidratados de cátions multivalentes [3]. $\mathrm{O}$ grupo de Novos Materiais (EEL-USP) vem desenvolvendo materiais adsorventes utilizando como método de preparação para os óxidos metálicos hidratados $\left(\mathrm{ZrO}_{2} \cdot \mathrm{nH}_{2} \mathrm{O}\right.$ e $\left.\mathrm{Nb}_{2} \mathrm{O}_{5} \cdot \mathrm{nH}_{2} \mathrm{O}\right)$ a 
precipitação em solução homogênea (PSH) e a precipitação convencional (PC). Estudou-se também as variáveis de preparação do $\mathrm{Nb}_{2} \mathrm{O}_{5} \cdot \mathrm{nH} \mathrm{H}_{2} \mathrm{O}$ como tipo de agente precipitante (amônia, uréia e carbonato de amônio), ordem de adição do agente precipitante e tempo de agitação $(4,5$ e 8 h).

O efeito da temperatura de precipitação na síntese dos óxidos de nióbio e de zircônio hidratados foi estudado utilizando temperaturas de decomposição de $45^{\circ} \mathrm{C}$ e $90^{\circ} \mathrm{C}$ [5]. Foi observado que a temperatura não causou mudanças físicas (valor do espaçamento interlamelar, grau de hidratação e grau de cristalinidade dos óxidos). Porém, foi constatado que a temperatura de síntese foi fundamental na resposta de adsorção dos íons prata e chumbo (II), com maior resposta de adsorção por parte do $\mathrm{Nb}_{2} \mathrm{O}_{5} \cdot \mathrm{nH}_{2} \mathrm{O}$ preparado a $90{ }^{\circ} \mathrm{C}$ e, para este, maior seletividade ao $\mathrm{Pb}^{2+}$ (resposta de 375,94 $\left.\mathrm{mg} \cdot \mathrm{g}^{-1}\right)$.

Surfactante é o termo usado para descrever os compostos que diminuem drasticamente a tensão superficial da água e formam agregados como micelas em meio aquoso. Os surfactantes são classificados pelos seus grupos hidrofílicos. Surfactantes aniônicos, catiônicos, anfóteros, e não-iônicos contêm ânions, cátions, íons anfóteros, e grupos polares nãoiônicos, respectivamente, como seus grupos hidrofílicos. Surfactantes aniônicos são usados principalmente como detergentes. Surfactantes catiônicos são particularmente úteis na fabricação de amaciantes e de condicionadores de cabelo. Surfactantes anfóteros são usualmente utilizados para aumentar o poder de detergência e/ou espuma dos surfatantes aniônicos. Surfactantes não-iônicos, mais conhecidos como emulsificantes, também demonstram forte detergência por sujeiras oleosas [6]. Os surfactantes catiônicos encontram grande aplicação em diversas indústrias destacando-se a química (pesticidas), papel, têxtil, plástico, tintas, cosméticos, produtos farmacêuticos e conservantes alimentícios [7-10]. Além disso, são freqüentemente usados na preparação de produtos de limpeza doméstica e de higiene pessoal como em desinfetantes bucais, pastas dentais, cremes de barbear, xampus e desodorantes, por possuírem, além de outras, propriedades anti-sépticas. É o caso do cloreto de cetilpiridinio, também designado por cloreto de hexadecilpiridinio que apresenta ação antimicrobiana sob bactérias gram negativas e que freqüentemente é utilizado em fórmulas para desinfetantes bucais [8].

O objetivo deste trabalho é estudar a capacidade de adsorção do surfactante catiônico brometo de cetiltrimetil amônio sobre diferentes matrizes inorgânicas. O estudo de remoção de surfactantes em efluentes é interessante uma vez que esses compostos provocam desequilíbrio no meio ambiente aquático por diminuir a tensão superficial e por reduzir o oxigênio dissolvido no processo de degradação microbiológica.

\section{EXPERIMENTAL}

\section{Preparação do óxido de nióbio hidratado}

Na precipitação em solução homogênea (PSH), o óxido de nióbio $\mathrm{V}$ hidratado foi obtido pela dissolução do $\mathrm{Nb}$ (produto da $4^{\mathrm{a}}$ fusão, Departamento de Materiais, EELUSP) a uma mistura ácida de $\mathrm{HNO}_{3}(65 \%) / \mathrm{HF}(40 \%)$ na relação 1:3 molar. Depois de todo o material solubilizado, adicionou-se o ácido bórico (20,0 g) e o precursor do agente precipitante (92,0 g de carbonato de amônio), gerando in situ as hidroxilas pela decomposição térmica do mesmo, sob aquecimento de $45^{\circ} \mathrm{C}$. O precipitado foi filtrado, lavado com água deionizada e seco a $50{ }^{\circ} \mathrm{C}$ em estufa. Um novo material foi preparado, seguindo todo procedimento descrito, modificando apenas a temperatura do meio reacional para 90 ${ }^{\circ} \mathrm{C}$. Utilizou-se para o método PSH, como agente precipitante, o carbonato de amônio e a uréia. A temperatura de trabalho para os materiais preparados pelo método PSH foi $90{ }^{\circ} \mathrm{C}$, que é a temperatura de decomposição da uréia [4, 11-13].

\section{Preparação do fosfato de nióbio hidratado}

O fosfato de nióbio hidratado foi preparado pela dissolução do nióbio metálico, usando um béquer de polietileno com uma mistura de ácido fluorídrico (40\%) e ácido nítrico concentrado na proporção (10:1). Após dissolução adicionou-se ácido fosfórico concentrado e a solução foi colocada para concentrar em banho-maria durante $34 \mathrm{~h}$ na temperatura de aproximadamente $60{ }^{\circ} \mathrm{C}$. Formou-se um precipitado branco gelatinoso que foi lavado com ácido nítrico $\left(5 \mathrm{~mol} . \mathrm{L}^{-1}\right)$, água deionizada e etanol e secado a $50^{\circ} \mathrm{C}$ até peso constante.

\section{Caracterização dos materiais preparados}

Os materiais foram caracterizados por termogravimetria (TG/DTG), microscopia eletrônica de varredura (MEV) e medida de área superficial específica pelo método BET. As curvas TG foram obtidas em uma termobalança Shimadzu TGA-50 em cadinho de platina aberto, com razão de aquecimento $20{ }^{\circ} \mathrm{C} \cdot \mathrm{min}^{-1}$ em $50 \mathrm{~mL} \cdot \mathrm{min}^{-1}$ em fluxo de nitrogênio numa faixa de temperatura entre a ambiente e $900{ }^{\circ} \mathrm{C}$.

A determinação da área superficial específica foi feita um analisador de adsorção gasosa Quantachrome Nova 1000 sob atmosfera de nitrogênio com fluxo de $0,5 \mathrm{~cm}^{3} \cdot \mathrm{s}^{-1}$. Foram feitos ainda dois pré-tratamentos, um a $50{ }^{\circ} \mathrm{C}$ em estufa a vácuo por $16 \mathrm{~h}$ e outro, no próprio porta amostra (célula) a $50{ }^{\circ} \mathrm{C}$ por $3 \mathrm{~h} \mathrm{com}$ manta aquecedora.

A fotomicrografia foi obtida em um microscópio eletrônico de varredura LEO 1450VP com elétrons secundários, acoplado a um espectrômetro de energia dispersiva (EDS). A amostra foi recoberta com pó de ouro para evitar o seu carregamento e fixada em um porta-amostra com fita carbono autocolante dupla face.

Estudo da adsorção do surfactante catiônico CTABr pelos modelos de Langmuir e de Freundlich

O estudo da remoção do sal de amônio quaternário CTABr foi feito pelo processo descontínuo, colocando em contato 
$0,15 \mathrm{~g}$ do material adsorvedor com $50 \mathrm{~mL}$ do surfactante. A faixa de concentração do sal de amônio quaternário utilizada estava abaixo da concentração micelar crítica (CMC), para evitar a formação de micelas. Com os resultados obtidos, utilizou-se o modelo de Langmuir e de Freundlich, que são freqüentemente usados para descrever isotermas de adsorção para aplicações em tratamento de águas e de efluentes [1418]. Para determinar as concentrações iniciais e finais (ou de equilíbrio, $C_{e}$ ) de CTABr, utilizou-se a metodologia descrita em [19]. Assim, sobre $12,00 \mathrm{~mL}$ de CTABr foram adicionados $0,24 \mathrm{~mL}$ de ácido pícrico em $\mathrm{NaOH} 0,002$ mol. $\mathrm{L}^{-1}$. Em seguida, colocou-se $6,00 \mathrm{~mL}$ do solvente metilisobutil-cetona (MIBK). Agitou-se então a mistura por $5 \mathrm{~min}$ para a completa extração do par iônico formado e separou-se a fase orgânica por centrifugação a $3500 \mathrm{rpm}$ durante $5 \mathrm{~min}$. Por meio de um espectrofotômetro UV-Visível Fentom 600 mediu-se a absorbância da fase orgânica a $375 \mathrm{~nm}$. Utilizouse o modelo linear segundo Langmuir e Freundlich, com os resultados obtidos para descrever o processo de remoção do surfactante [15].

\section{RESULTADOS E DISCUSSÃO}

As Figs. 1, 2 e 3 mostram as isotermas de adsorção de CTABr pelo modelo de Langmuir para os materiais preparados, respectivamente. As Figs. 4,5 e 6 mostram as isotermas de adsorção de CTABr pelo modelo de Freundlich para os mesmos materiais.

Com as isotermas de Langmuir e de Freundlich obtidas, calcularam-se os parâmetros de adsorção do surfatante para os materiais. A Tabela I mostra os parâmetros das isotermas de Langmuir, além dos respectivos coeficientes de correlação $r^{2}$. A Tabela II mostra os parâmetros das isotermas de Freundlich também para ambos materiais, além dos respectivos coeficientes de correlação.

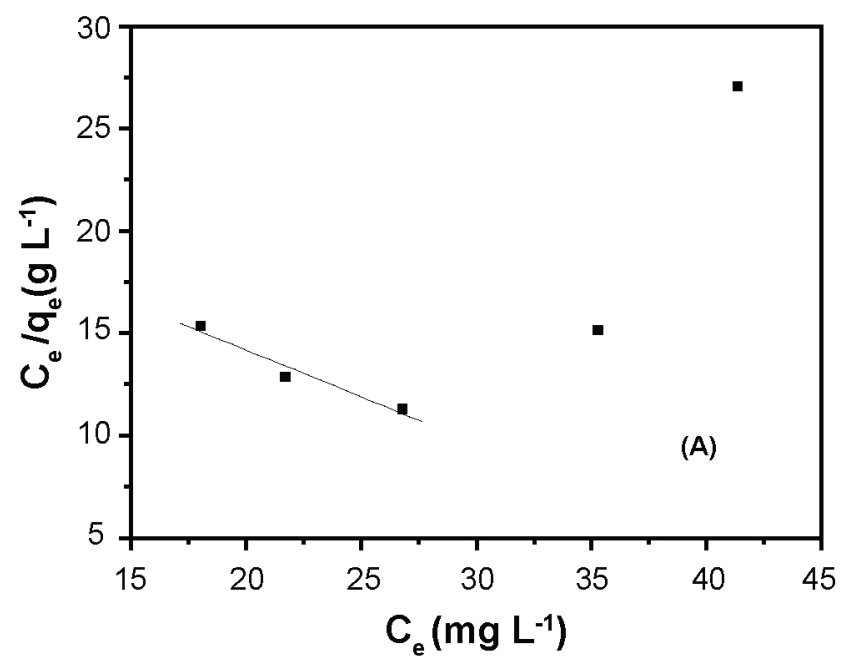

Figura 1: Isotermas de adsorção de Langmuir para $\mathrm{CTABr}$ utilizando $\mathrm{Nb}_{2} \mathrm{O}_{5} \cdot \mathrm{nH}_{2} \mathrm{O}$ preparado a $45^{\circ} \mathrm{C}(\mathrm{A})$.

[Figure 1: Langmuir adsorption isotherms for CTABr using $\mathrm{Nb}_{2} \mathrm{O}_{5}$. $n \mathrm{H}_{2} \mathrm{O}$ prepared at $\left.45^{\circ} \mathrm{C}(\mathrm{A})\right]$.

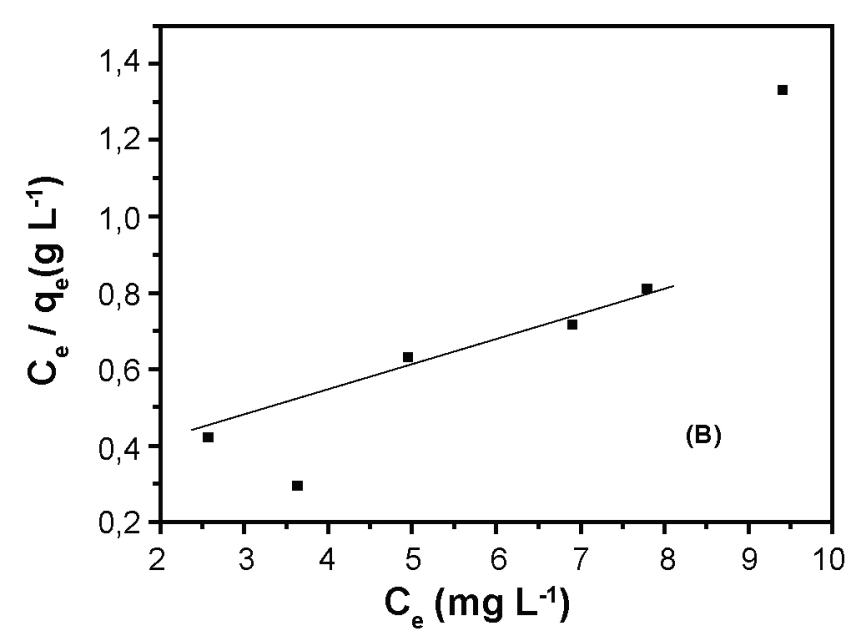

Figura 2: Isotermas de adsorção de Langmuir para CTABr utilizando $\mathrm{Nb}_{2} \mathrm{O}_{5} \cdot \mathrm{nH}_{2} \mathrm{O}$ preparado a $90{ }^{\circ} \mathrm{C}$.

[Figure 2: Langmuir adsorption isotherms for CTABr using $\mathrm{Nb}_{2} \mathrm{O}_{5}$. $n \mathrm{H}_{2} \mathrm{O}$ prepared at $\left.90^{\circ} \mathrm{C}\right]$.

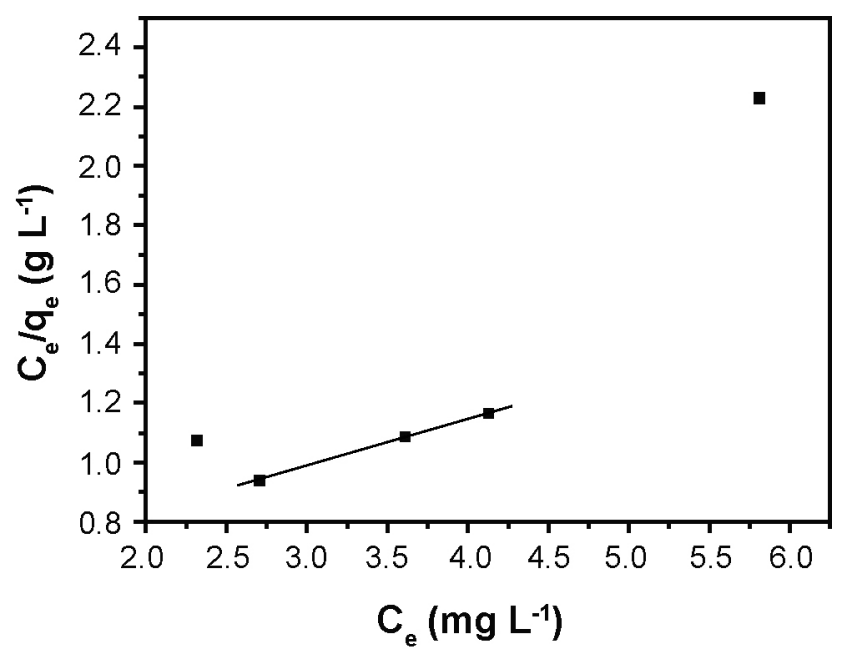

Figura 3: Isotermas de adsorção de Langmuir para CTABr utilizando $\mathrm{NbOPO}_{4} \cdot \mathrm{nH}_{2} \mathrm{O}$.

[Figure 3: Langmuir adsorption isotherms for CTABr using $\mathrm{NbO}$ $\left.\mathrm{PO}_{4} \cdot \mathrm{nH}_{2} \mathrm{O}\right]$.

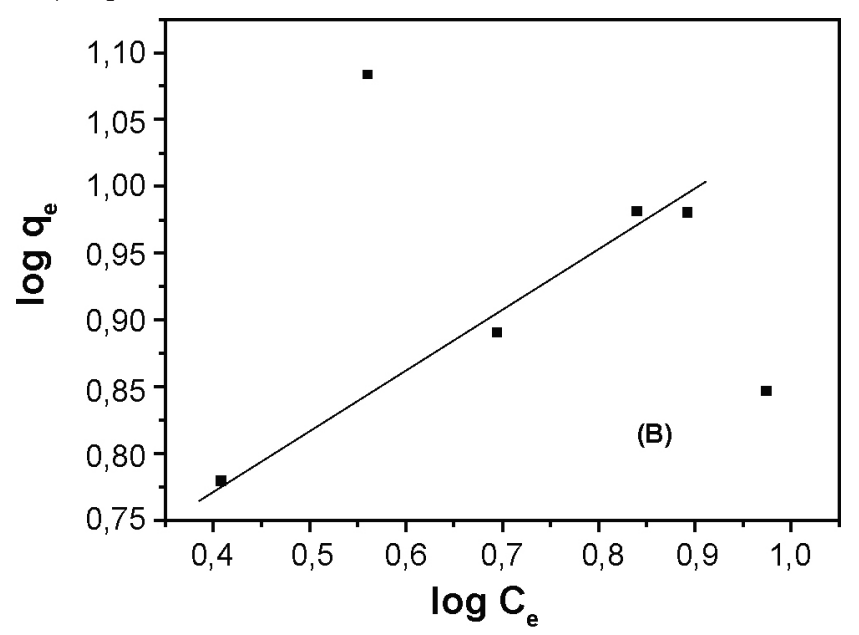

Figura 4: Isotermas de adsorção de Freundlich para CTABr utilizando $\mathrm{Nb}_{2} \mathrm{O}_{5} \cdot \mathrm{nH}_{2} \mathrm{O}$ preparado a $45^{\circ} \mathrm{C}$ (A).

[Figure 4: Freundlich adsorption isotherms for $\mathrm{CTABr}$ using $\mathrm{Nb}_{2} \mathrm{O}_{5} . n \mathrm{H}_{2} \mathrm{O}$ prepared at $\left.45^{\circ} \mathrm{C}(\mathrm{A})\right]$. 


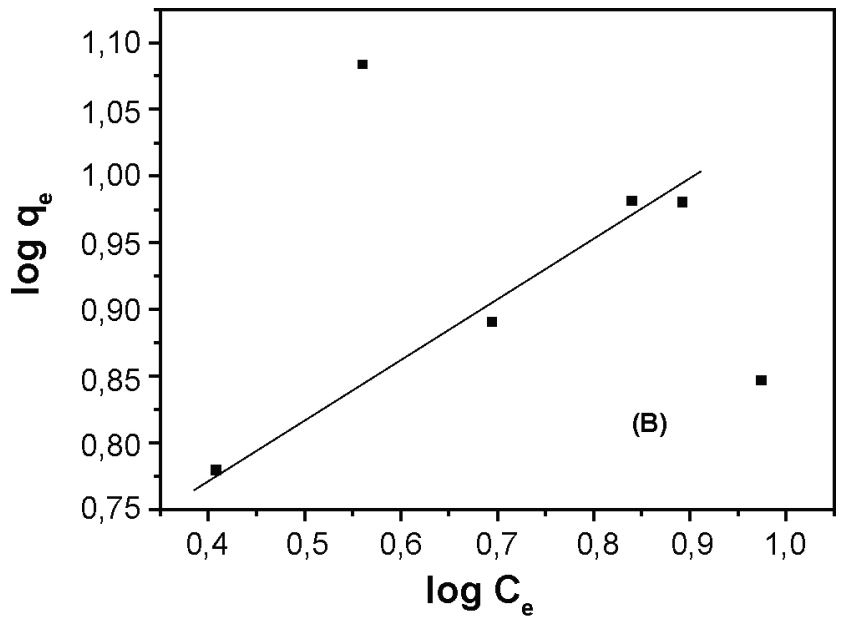

Figura 5: Isotermas de adsorção de Freundlich para CTABr utilizando $\mathrm{Nb}_{2} \mathrm{O}_{5} \cdot \mathrm{nH}_{2} \mathrm{O}$ preparado a $90{ }^{\circ} \mathrm{C}(\mathrm{B})$.

[Figure 5: Freundlich adsorption isotherms for CTABr using $\mathrm{Nb}_{2} \mathrm{O}_{5} \cdot n \mathrm{H}_{2} \mathrm{O}$ prepared at $\left.90{ }^{\circ} \mathrm{C}(\mathrm{B})\right]$.

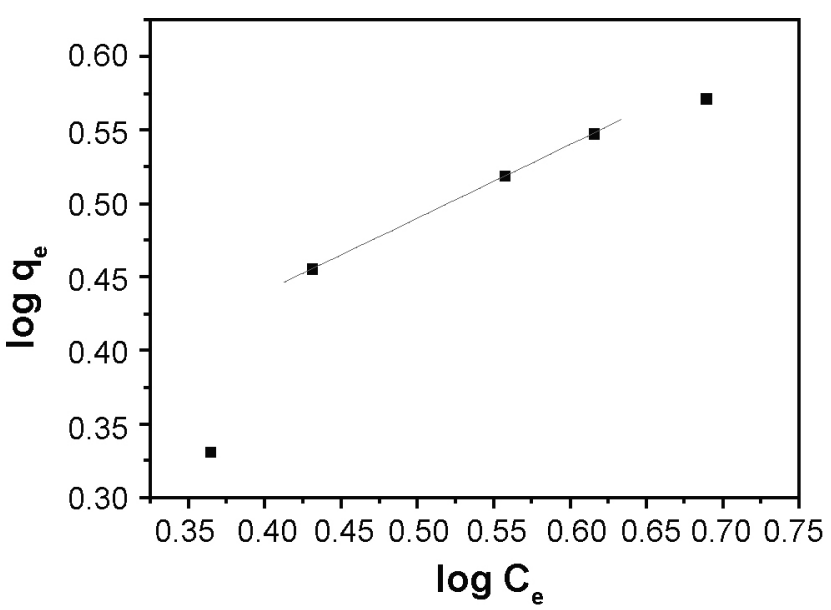

Figura 6: Isotermas de adsorção de Freundlich para CTABr utilizando $\mathrm{NbOPO}_{4} \cdot \mathrm{nH}_{2} \mathrm{O}$.

[Figure 6: Freundlich adsorption isotherms for CTABr using $\left.\mathrm{NbOPO}_{4} \cdot \mathrm{nH}_{2} \mathrm{O}\right]$.

Pelas Figs. 1 a 6 e pelos coeficientes de correlação $r^{2}$ das Tabelas I e II, os modelos de Langmuir e de Freundlich se ajustam aos dados experimentais do processo de adsorção do CTAB dos materiais. Porém, comparando os resultados dos coeficientes de correlação $r^{2}$ nas Tabelas I e II, verifica-se que o modelo de isoterma de Freundlich melhor se ajusta aos resultados experimentais obtidos. Pelo parâmetro $R_{L}$ de Langmuir na Tabela I vê-se que a adsorção do surfactante no óxido de nióbio preparado a $45{ }^{\circ} \mathrm{C}$ não é favorável $\left(R_{L}>1\right)$, enquanto que a adsorção do surfactante no óxido de nióbio preparado a $90{ }^{\circ} \mathrm{C}$ e no fosfato de nióbio hidratado é favorável $\left(0<R_{L}<1\right)$. Pelo parâmetro $n$ (Tabela II) do modelo de Freundlich, uma vez que para o $\mathrm{Nb}_{2} \mathrm{O}_{5} \cdot \mathrm{nH}_{2} \mathrm{O}$ preparado a $45{ }^{\circ} \mathrm{C}$ e para o fosfato de nióbio hidratado não é favorável para o $\mathrm{Nb}_{2} \mathrm{O}_{5}$. $\mathrm{nH}_{2} \mathrm{O}$ preparado a $90{ }^{\circ} \mathrm{C}$, encontra entre 2 e 10 , adsorção favorável. A constante $Q_{o}$ (Tabela I), relacionada com a capacidade de adsorção máxima, do modelo de Langmuir,
Tabela I - Capacidade máxima de adsorção $Q_{0}\left(\mathrm{mg} \cdot \mathrm{L}^{-1}\right)$, energia de adsorção $b\left(\mathrm{~L}^{\mathrm{m}} \mathrm{mg}^{-1}\right)$ e parâmetro de equilíbrio $R_{L}$ do modelo de isoterma de Langmuir para o surfactante CTABr.

[Table I - Maximum adsorption capacity $Q_{0}\left(m g . L^{-1}\right)$, adsorption energy $b\left(L^{2} \mathrm{mg}^{-1}\right)$ and equilibrium parameter $R_{L}$ of Langmuir isotherm model for surfactant CTABr].

\begin{tabular}{ccccc}
\hline $\begin{array}{c}\text { Material } \\
\text { Adsorvente }\end{array}$ & $\begin{array}{c}\mathrm{Q}_{\mathrm{o}} \\
\left(\mathrm{mg} \cdot \mathrm{g}^{-1}\right)\end{array}$ & $\begin{array}{c}\mathrm{b} \\
\left(\mathrm{L} \cdot \mathrm{mg}^{-1}\right)\end{array}$ & $\mathrm{R}_{\mathrm{L}}$ & $\mathrm{r}^{2}$ \\
\hline $\begin{array}{c}\mathrm{Nb}_{2} \mathrm{O}_{5} \cdot \mathrm{nH}_{2} \mathrm{O} \\
\left(45^{\circ} \mathrm{C}\right)\end{array}$ & $-2,19$ & $-0,020$ & 3,041 & 0,9755 \\
$\begin{array}{c}\mathrm{Nb}_{2} \mathrm{O}_{5} \cdot \mathrm{nH}_{2} \mathrm{O} \\
\left(90^{\circ} \mathrm{C}\right)\end{array}$ & 14,13 & 0,278 & 0,089 & 0,9897 \\
\begin{tabular}{l}
$\mathrm{NbOPO}_{4} \cdot \mathrm{nH}_{2} \mathrm{O}$ \\
\hline
\end{tabular} & 7,48 & 0,246 & 0,194 & 0,999 \\
\hline
\end{tabular}

Tabela II - Capacidade de adsorção $K f\left(\mathrm{mg} \mathrm{g}^{-1}\right)$ e intensidade de adsorção (n) do modelo de isoterma de Freundlich para o surfactante CTABr.

[Table II - Indicator of adsorption capacity $K f\left(\mathrm{mg} \mathrm{g}^{-1}\right)$ and adsorption intensity (n) of Freundlich isotherm model for surfactant $C T A B r]$.

\begin{tabular}{cccc}
\hline $\begin{array}{c}\text { Material } \\
\text { Adsorvente }\end{array}$ & $\mathrm{Kf}\left(\mathrm{mg} \mathrm{g}^{-1}\right)$ & $\mathrm{n}$ & $\mathrm{r}^{2}$ \\
\hline $\begin{array}{c}\mathrm{Nb}_{2} \mathrm{O}_{5} \cdot \mathrm{nH}_{2} \mathrm{O} \\
\left(45^{\circ} \mathrm{C}\right)\end{array}$ & $7,065 \cdot 10^{-3}$ & 0,56 & 0,9986 \\
$\mathrm{Nb}_{2} \mathrm{O}_{5} \cdot \mathrm{nH}_{2} \mathrm{O}$ & 3,976 & 2,29 & 0,9915 \\
$\left(90^{\circ} \mathrm{C}\right)$ & 1,812 & 1,938 & 0,998 \\
$\mathrm{NbOPO}_{4} \cdot \mathrm{nH}_{2} \mathrm{O}$ & 1,968 & \\
\hline
\end{tabular}

mostra melhor resultado para o $\mathrm{Nb}_{2} \mathrm{O}_{5} \cdot \mathrm{nH}_{2} \mathrm{O}$ preparado a $90{ }^{\circ} \mathrm{C}\left(14,13 \mathrm{mg} \cdot \mathrm{g}^{-1}\right)$ seguido do fosfato de nióbio hidratado $\left(7,48 \mathrm{mg} \cdot \mathrm{g}^{-1}\right)$ e do $\mathrm{Nb}_{2} \mathrm{O}_{5} \cdot \mathrm{nH}_{2} \mathrm{O}$ preparado a 45 ${ }^{\circ} \mathrm{C}\left(-2,19 \mathrm{mg} \cdot \mathrm{g}^{-1}\right)$.

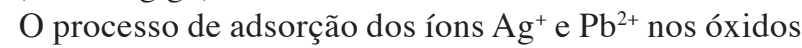
de nióbio e de zircônio hidratados preparados a $45^{\circ} \mathrm{C}$ e a $90{ }^{\circ} \mathrm{C}$ foi estudado utilizando carbonato de amônio como precursor de precipitação dos óxidos metálicos hidratados [5]. No estudo de adsorção do íon chumbo, obtiveram-se capacidade de adsorção máxima $Q_{0}$ igual a $218,34 \mathrm{mg} \cdot \mathrm{g}^{-1}$ para o $\mathrm{Nb}_{2} \mathrm{O}_{5} \cdot \mathrm{nH}_{2} \mathrm{O}$ preparado a $45^{\circ} \mathrm{C}$ e igual a 375,94 $\mathrm{mg} . \mathrm{g}^{-1}$ para o material preparado a $90{ }^{\circ} \mathrm{C}$. No estudo de adsorção dos íons prata, os autores obtiveram capacidade de adsorção máxima $Q_{o}$ igual a $108,23 \mathrm{mg} \cdot \mathrm{g}^{-1}$ para o $\mathrm{Nb}_{2} \mathrm{O}_{5}$. $\mathrm{nH}_{2} \mathrm{O}$ preparado a $45^{\circ} \mathrm{C}$ e igual a $110,01 \mathrm{mg} \cdot \mathrm{g}^{-1}$ para $\mathrm{o}$ material preparado a $90{ }^{\circ} \mathrm{C}$. Neste estudo, foi encontrada adsorção unicamente favorável.

O valor da área superficial específica para o material preparado a $45{ }^{\circ} \mathrm{C}$ foi $58 \mathrm{~m}^{2} \cdot \mathrm{g}^{-1}$ para o óxido metálico hidratado preparado a $90{ }^{\circ} \mathrm{C} \quad 70 \mathrm{~m}^{2} \cdot \mathrm{g}^{-1}$ e para o fosfato 


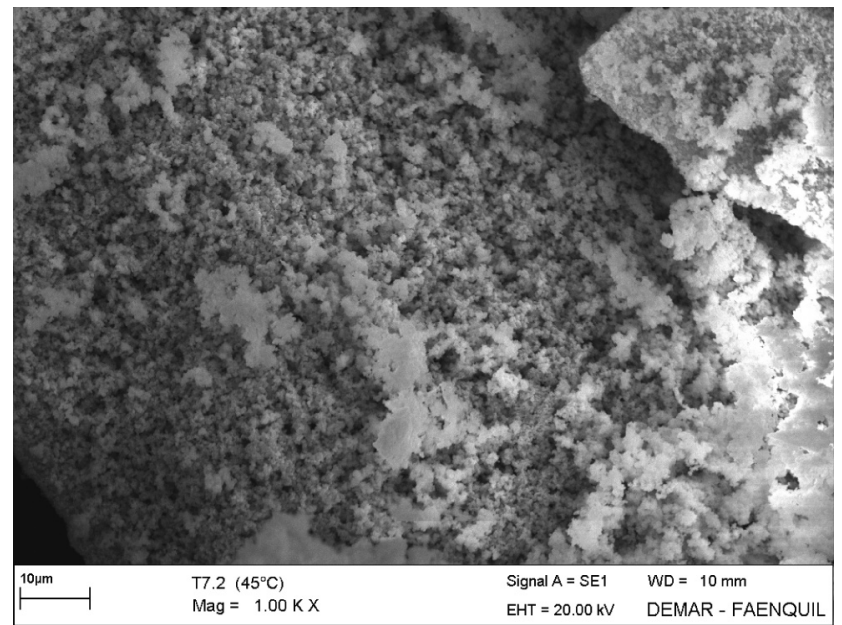

(A)

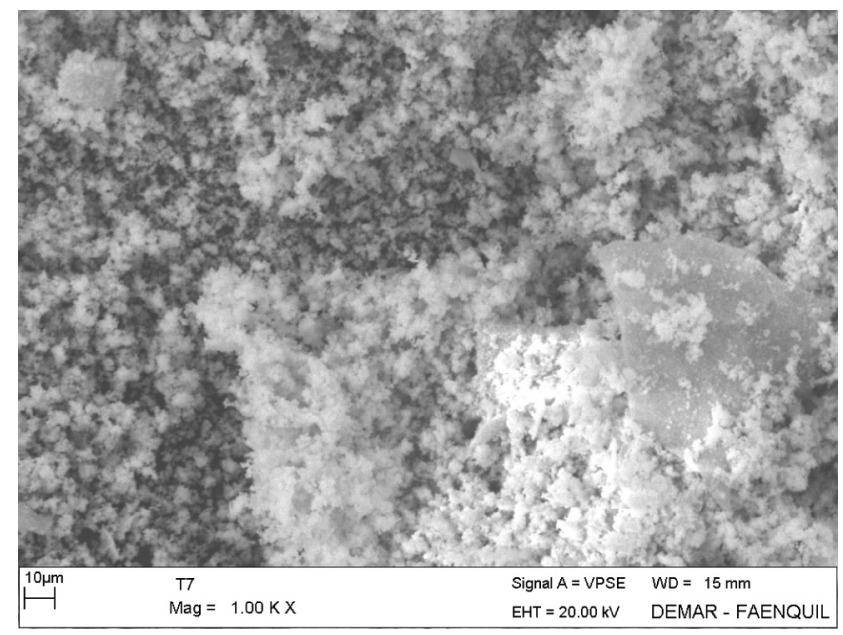

(B)

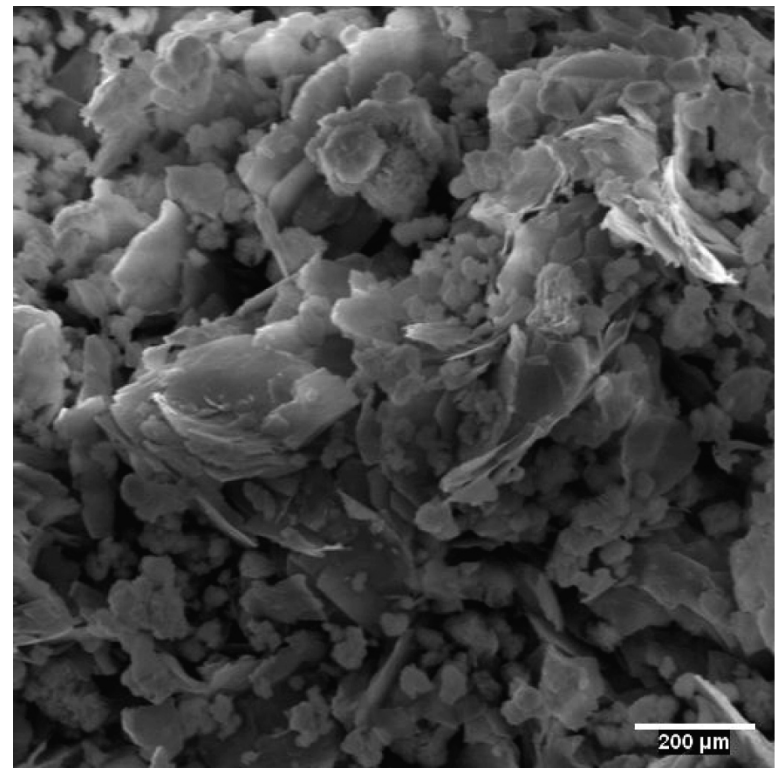

(C)

Figura 7: Micrografias obtidas por microscopia eletrônica de varredura de $\mathrm{Nb}_{2} \mathrm{O}_{5} \cdot \mathrm{nH}_{2} \mathrm{O}$ preparado a $45{ }^{\circ} \mathrm{C}(\mathrm{A}), 90{ }^{\circ} \mathrm{C}(\mathrm{B})$ e do $\mathrm{NbOPO}_{4} \cdot \mathrm{nH}_{2} \mathrm{O}(\mathrm{C})$.

[Figure 7: Scanning electron microscopy micrographs of $\mathrm{Nb}_{2} \mathrm{O}_{5}$. $n \mathrm{H}_{2} \mathrm{O}$ prepared at $45^{\circ} \mathrm{C}(\mathrm{A}), 90{ }^{\circ} \mathrm{C}(\mathrm{B})$ and $\left.\mathrm{NbOPO}_{4} \cdot \mathrm{nH}_{2} \mathrm{O}(\mathrm{C}).\right]$ de nióbio hidratado foi $8 \mathrm{~m}^{2} \cdot \mathrm{g}^{-1}$. Verifica-se, portanto, que não há mudança significativa no valor da área superficial específica para o óxido metálico hidratado preparado em diferentes temperaturas. O carvão ativo em pó comercial com área superficial específica de $900 \mathrm{~m}^{2} \cdot \mathrm{g}^{-1}$ foi utilizado [20]. Área superficial específica de $224,8 \mathrm{~m}^{2} \cdot \mathrm{g}^{-1}$ foi obtida para o óxido de nióbio hidratado preparado com uréia (precursor de precipitação) [13]. Área específica de $123 \mathrm{~m}^{2} \cdot \mathrm{g}^{-1}$ foi obtida para o óxido de nióbio hidratado preparado com carbonato de amônio, com temperatura de precipitação de $90{ }^{\circ} \mathrm{C}$ e tempo de precipitação de $4 \mathrm{~h}$ [13].

As Figs. 7A, 7B e 7C mostram as micrografias dos materiais preparados a $45{ }^{\circ} \mathrm{C}$ e a $90{ }^{\circ} \mathrm{C}$ e do fosfato de nióbio hidratado, respectivamente. Os óxidos metálicos hidratados são constituídos por grãos de morfologia irregular. A superfície de ambos os materiais (preparados a $45^{\circ} \mathrm{C}$ e a $90{ }^{\circ} \mathrm{C}$ ) apresentam-se porosa em quase toda sua extensão, o que pode favorecer o processo de adsorção de íons [12]. Ambos materiais contém, ainda, regiões pontuais que não apresentam porosidade, principalmente o $\mathrm{Nb}_{2} \mathrm{O}_{5} \cdot \mathrm{nH}_{2} \mathrm{O}$ preparado a $90{ }^{\circ} \mathrm{C}$ (Fig. 7B) que mostra um grão sobreposto com superfície lisa. A Fig. $7 \mathrm{C}$ apresenta a fotomicrografia do fosfato de nióbio hidratado com uma superfície com grandes aglomerados e uma superfície porosa na forma de escamas com uma ampliação de 2000 vezes.

\section{CONCLUSÕES}

A temperatura do sistema reacional não acarretou mudanças físicas significativas na preparação do óxido de nióbio hidratado a $45{ }^{\circ} \mathrm{C}$ e a $90{ }^{\circ} \mathrm{C}$. Porém observaram-se mudanças nas propriedades químicas, ou seja, na remoção do sal de amônio quaternário CTABr. Por meio das isotermas de Langmuir e Freundlich verifica-se que $\mathrm{Nb}_{2} \mathrm{O}_{5}$. $\mathrm{nH}_{2} \mathrm{O}$ preparado a $90{ }^{\circ} \mathrm{C}$ apresentou melhor capacidade de adsorção máxima com resposta de $14,13 \mathrm{mg} \cdot \mathrm{g}^{-1}$, o que justifica a escolha da temperatura mais elevada $\left(90^{\circ} \mathrm{C}\right)$ na preparação do óxido de nióbio hidratado para a referida aplicação.

\section{NOMENCLATURA}

$C_{e}$ : concentração do metal após atingir o equilíbrio no processo de adsorção $\left(\mathrm{mg} \cdot \mathrm{L}^{-1}\right)$.

$q_{e}$ : quantidade de íon adsorvido na espécie adsorvente (mg. $\left.\mathrm{g}^{-1}\right)$, segundo modelo Langmuir.

$Q_{0}$ : constante relacionada com a capacidade máxima de adsorção do material adsorvente (mg.g $\mathrm{g}^{-1}$ ), segundo modelo Langmuir.

$R_{L}$ : característica essencial da isoterma de Langmuir (adimensional).

Kf: capacidade de adsorção do modelo de Freundlich (mg. $\left.\mathrm{g}^{-1}\right)$.

$n$ : intensidade de adsorção segundo modelo de Freundlich (adimensional) 


\section{AGRADECIMENTOS}

Os autores agradecem o apoio financeiro do CNPq e da CAPES.

\section{REFERÊNCIAS}

[1] M. Ahmaruzzaman, D. K. Sharma, J. Colloid Interface Sci 287, 1 (2005) 14-24.

[2] L. M. Nunes, C. Airoldi, Química Nova 24, 6 (2001) 799-807.

[3] A. Nilchi, B. Malek, M. G. Maragheh, A. Khanchi, Rad. Phys. Chem. 68, 5 (2003) 837-842.

[4] G. L. J. P. Silva, M. L. C. P. Silva, T. Caetano, Mater. Res. 5, 2 (2002) 149-153.

[5] A. L. C. Peixoto, G. L. J. P. Silva, M. L. C. P. Silva, Cerâmica 52, 324 (2006) 249-254.

[6] K. Tsujii, Surface ativity: principles, phenomena and applications, Academic Press, San Diego, EUA (1998).

[7] M. N. Abbas, G. A. Mostafa, M. A. Homada, Talanta 53 (2000) 425-432.

[8] P. C. S. Baptista, A. N. Araújo, M. C. B. S. M. Montenegro, Química Nova 26, 4 (2003) 475-478.

[9] L. Campanella, L. Aiello, C. Colapicchioni, M.
Tomassetti, Analysis 24 (1996) 387-391.

[10] M. B. Simon, A. E. Cózar, L. M. Polo Díez, Analyst 115 (1990) 337-339.

[11] M. L. C. P. Silva, G. V. Tagliaferro, G. L. J. P. Silva, Anais Assoc. Bras. Quim. 50, 2 (2001) 83-85.

[12] G. V. Tagliaferro, Diss. Mestrado, Faculdade de Engenharia Química de Lorena, Lorena, SP (2003).

[13] G. V. Tagliaferro, M. L. C. P. Silva, G. L. J. P. Silva, Química Nova 28, 2 (2005) 250-254.

[14] P. H. F. Pereira, M. L. C. P. Silva, Química Nova 32, 1 (2009) 7-11.

[15] L. A. Rodigues, M. L. C. P. Silva, Colloids Surfaces A: Physicochem. Eng. Aspects 334 (2009) 191-196.

[16] D. A. Fungaro, M. G. Silva, Química Nova 25, 6B (2002) 1081-1085.

[17] M. M. Abou-Mesalam, Colloids Surfaces A 225 (2003) 85-94.

[18] M. M. Nassar, K. T. Ewida, E. E. Ebrahiem, Y. H. Magdy, M. H. Mheaedi, Adsorption Science and Technology 22, 1 (2004) 25-37.

[19] I. Sheiham, T. A. Pinfold, Analyst 94 (1969) 387-388. [20] A. Gurses, M. Yalcin, M. Sozbilir, C. Dogar, Fuel Processing Technology 81, 1(2003) 57-66. (Rec. 23/09/2008, Rev. 06/03/2009, Ac. 10/06/2009) 